\title{
Mitigation of Voltage sag and Harmonics in Grid connected Wind Energy System using STATCOM
}

\author{
P. Malathy ${ }^{1}$, M. Karthiga ${ }^{2}$ \\ ${ }^{I}$ (Associate Prof., Dept. of EEE., PSNA College of Engg. \& Tech., Anna University Chennai, Tamil Nadu,India) \\ ${ }^{2}$ (PG Scholar, Dept. of EEE, PSNA College of Engg. \& Tech.,Anna University Chennai, Tamil Nadu, India)
}

\begin{abstract}
Power quality gains its importance with the introduction of sophisticated electrical gadgets. The performances of these devices are sensitive to the quality of input power supply. Various power quality problems results in failure or mal-operation of end user equipment. Some of the major power quality issues are voltage sag, voltage swell and harmonics. To solve these problems, capacitors, voltage regulators and filters, are conventionally used. These techniques involve inherent drawbacks. So it is proposed to use Flexible AC Transmission System (FACTS) devices for the mitigation of power quality problems. With the usage of these devices, drawbacks associated with conventional methods can be overcome easily. The application of FACTS devices provides faster control and enhances the way of using the transmission system at their rated thermal capability. In this work, it is proposed to use Static Var Compensator (STATCOM) for mitigating voltage sag and harmonics by providing proper reactive power support. The device is modelled and simulated using MATLAB-SIMULINK. In order to validate the proposed approach, it is tested with three phase fault simulated in the designed model. The graphical, numerical results with and without STATCOM are compared to measure the effectiveness of control.
\end{abstract}

Keywords: Distortion, Harmonics, Power Quality, STATCOM, Voltage sag.

\section{Introduction}

The term Power Quality (PQ) is associated with electrical distribution and utilization systems. Poor quality of power is the one, which experience any voltage, current or frequency deviation, from normal operation. For ideal electrical systems, the supplied power should have perfect current and voltage sinusoidal waveforms, being safe and reliable. The electric utilities can control the voltage levels but, are unable to control the current, since the load profile dictates the shape of the current waveform. It is the responsibility of the utility, to maintain the quality of power at all times. A Flexible AC Transmission System (FACTS) is a power electronic based device which provides better power flow control and dynamic stability by controlling one or more ac transmission system parameters like, voltage, phase angle and impedance. The STATCOM is a shunt type FACTS device, used to control voltage through reactive power compensation. The use of STATCOM helps to regulate system voltage and to improve dynamic stability. STATCOM consists of inverters with a capacitor in its dc side, coupling transformer, and a control system. The inverters are switched with a single pulse per period. The transformers are connected to provide harmonic minimization. The equipment action is made through continuous and quick control of capacitive or inductive reactive power. Its output voltage of STATCOM is in the form of pulses that makes the system voltage sinusoidal.

Various power quality issues and methods of mitigation have been discussed in [1-3]. A power system is a complex interconnected structure with generation, transmission and distribution sectors as its components. The power from generation system is connected to the distribution system through long transmitting lines. The quality of power has a direct economic and financial impact on both utilities and industrial customers. Major power quality problems occur when a nonstandard voltage, current or frequency results in failure or maloperation of end user equipments. The most important PQ issues are voltage sag [4, 5], and harmonics [6]. To reduce the severity of $\mathrm{PQ}$ problems, mitigation devices can be placed in the transmission and distribution systems. The concept of Flexible AC Transmission Systems (FACTS) was introduced by N.G. Hingorani to combat with the power quality issues that originates from transmission systems [7-9]. Many types of FACTS devices are used for controlling and optimizing the flow of electrical power in power transmission lines [10]. This equipment makes use of large rating ( $4500 \mathrm{~V}$ to $6000 \mathrm{~V}, 4000 \mathrm{~A}$ to $6000 \mathrm{~A})$ Gate Turn-Off thyristors (GTO) in high power inverter configurations that can be controlled to behave as three-phase sinusoidal voltage sources. These devices are operated synchronously with the transmission line and may be connected either in parallel, producing controllable shunt reactive current for voltage regulation, or in series with the line, for controlling the flow of power directly. The family of these equipments includes the STATCOM [11-13]. MATPOWER [14] is an open-source Matlab-based power system simulation package that provides a high-level set of power flow, Simulink and other tools targeted toward researchers, educators, and students. 


\section{Power Quality Problems}

Variation of electric load in the power system is usually nonlinear. The nonlinear variation of loads creates continuous power quality problems, which are difficult to detect. The most important contributor to power quality problems is the customers or end-user electric loads. The customers often use sensitive type nonlinear load in all sectors like, industrial, commercial and residential. Power Quality issues can be roughly broken into a number of sub-categories. Voltage dip is short-term reduction in voltage for duration less than half a second. Voltage sag means reduction in amplitude ranging from $10 \%$ to $90 \%$ and a duration lasting for half a cycle to one minute. Voltage swell can be defined as an increase in rms voltage or current, at the power frequency for duration lasting from 0.5 cycles to 1 min. Voltage spikes, impulses or surges are abrupt, nonperiodic and brief increase in voltage level. Voltage transients are temporary, undesirable voltages that appear on the power supply line. Transients are high over-voltage disturbances (up to 20KV) that last for a very short time. A harmonic frequency is any sinusoidal frequency, which is a multiple of the fundamental frequency. Harmonic frequencies can be even or odd multiples of the sinusoidal fundamental frequency. Flicker is a visual irritation and it also introduces harmonic components in the power supply.

\subsection{Static Synchronous Compensator (STATCOM)}

\section{Methodology}

The STATCOM is a shunt connected reactive power compensation device that is capable of generating and / or absorbing reactive power. The output of STATCOM can be varied to control specific parameters of an electric power system. It is a solid state switching converter capable of generating or absorbing reactive power at its output terminals when it is fed from, an energy source or energy storage device at its input terminals. The STATCOM is a Voltage Source Converter (VSC) in which the input dc voltage produces a set of three phase ac output voltages. All the three phase voltages are displaced equally in phase and coupled to the corresponding ac system voltage through a small reactance. The input dc voltage is provided by an energy storage capacitor.

\subsection{Working principle of a STATCOM}

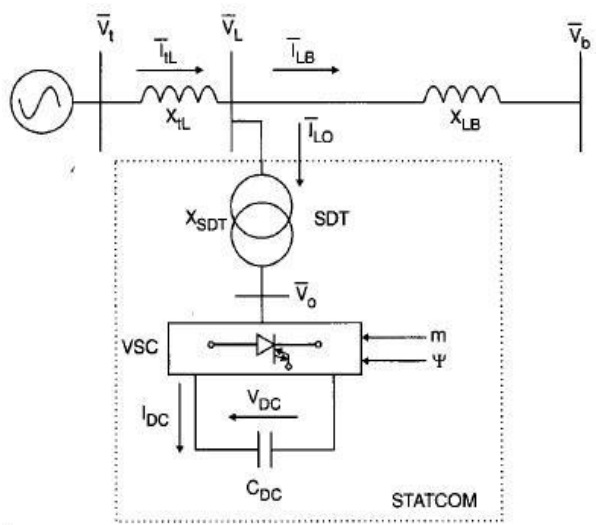

Fig.1 STATCOM operation

Fig.1 illustrates the working principle of STATCOM. The real $(\mathrm{P})$ and reactive power $(\mathrm{Q})$ of STATCOM is given by equation (1) and (2):

$$
\begin{aligned}
& \mathrm{P}=\mathrm{V}_{1} \mathrm{~V}_{2} \sin \frac{\delta}{\mathrm{x}} \\
& \mathrm{Q}=\mathrm{V}_{1}\left(\mathrm{~V}_{1}-\mathrm{V}_{2} \cos \delta\right) / \mathrm{x}
\end{aligned}
$$

\footnotetext{
Where

$\mathrm{V}_{1} \quad$ - $\quad$ line to line voltage of source 1 .

$\mathrm{V}_{2} \quad-\quad$ line to line voltage of source 2 .

$\mathrm{x} \quad-\quad$ reactance of interconnection and filters.

$\delta \quad \quad-\quad$ Phase angle of $\mathrm{V}_{1}$ with respect to $\mathrm{V}_{2}$.
}

In steady state operation, the voltage $V_{1}$ generated by the VSC is in phase with $V_{2}(\delta=0)$. If $V_{1}$ is lower than $V_{2}$, Q is flowing from $V_{1}$ to $V_{2}$ that means STATCOM is absorbing reactive power. On the reverse, if $V_{1}$ is higher than $\mathrm{V}_{2}$, Q is flowing from $\mathrm{V}_{2}$ to $\mathrm{V}_{1}$ that means STATCOM is generating reactive power. The amount of reactive power generation or absorption $\left(\mathrm{Q}_{\text {flow }}\right)$ is given by equation (3):

$$
\mathrm{Q}_{\text {flow }}=\left(\mathrm{V}_{1} *\left(\mathrm{~V}_{1}-\mathrm{V}_{2}\right)\right) / \mathrm{x}
$$


The input capacitor of VSC acts as a dc voltage source. In steady state, the voltage $\mathrm{V}_{2}$ has to be phase shifted slightly behind $\mathrm{V}_{1}$, in order to compenstate for tranformer losses and to keep the capacitor charged. VSC can be designed using GTO based square wave inverters and special interconnection transformers. Four sets of three-level inverters are used to build a 48-step voltage waveform. Special interconnection transformers are used to neutralize harmonics contained in the square waves generated by individual. In this type of VSC, the fundamental component of voltage $V_{1}$ is proportional to the voltage $V_{d c}$, which has to be varied for controlling the reactive power. VSC can also be designed using Insulated Gate Bipolar Transistor (IGBT) based Pulse Width Modulation (PWM) inverters. This type of inverter uses PMW technique to synthesis a sinusoidal waveform from a dc voltage source with a typical chopping frequency of a few $\mathrm{KHz}$. Harmonic voltages are cancelled by connecting filters at the ac side of the VSC. This type of VSC uses, a fixed dc voltage $\mathrm{V}_{\mathrm{dc}}$. Voltage $\mathrm{V}_{2}$ is varied by changing the modulation index of the PWM inverter.

\subsection{VI characteristics of STATCOM}

The STATCOM can be operated either in voltage regulation mode or in reactive power control mode. In voltage regulation mode, the voltage is kept within permissible limits. The V-I characteristics when STATCOM is operated in voltage regulation mode which is shown in Fig.2. In reactive power control mode, the reactive power output is maintained constant.

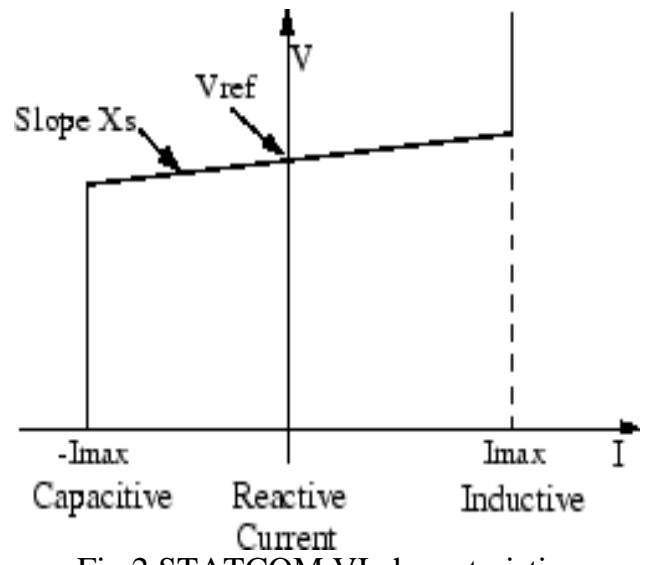

Fig.2 STATCOM VI characteristics

As long as, the reactive current stays within minimum and maximum current values imposed by the converter rating, the output voltage is regulated at the reference voltage, $\mathrm{V}_{\text {ref }}$. Normally, the voltage drop is between $1 \%$ and $4 \%$, at maximum reactive power output and it is indicated as the slope of VI characteristics. In the voltage regulation mode, the output voltage is described by equation (4):

Where

$$
\mathrm{V}=\mathrm{V}_{\text {ref }}+\mathrm{x}_{\mathrm{s}} \mathrm{I}
$$

$\mathrm{V} \quad$ - Positive sequence voltage in per unit.

I - Reactive current.

$\mathrm{x}_{\mathrm{s}} \quad-\quad$ Slope or drop reactance.

$\mathrm{P}_{\text {nom }} \quad-$ Three phase nominal power of the converter.

\subsection{Wind Energy Generating System}

Wind generations are based on, constant speed topologies with pitch control turbine. The induction generator is used in the proposed scheme, because of its simplicity, it does not require a separate field circuit, it can accept constant and variable loads, and has natural protection against short circuit. The real power output $\left(\mathrm{P}_{\text {wind }}\right)$ of a wind energy system is given in equation (5):

$$
\mathrm{P}_{\text {wind }}=\frac{\rho \mathrm{a} \mathrm{v}^{3}}{2}
$$

where $\rho(\mathrm{kg} / \mathrm{m})$ is the air density and a $(\mathrm{m})$ is the area swept out by turbine blade, $\mathrm{v}$ is the wind speed in $\mathrm{m} / \mathrm{s}$. It is not possible to extract all kinetic energy of wind, thus it extracts a fraction of power in wind, called power coefficient $\mathrm{Kp}$ of the wind turbine. The relation between $\mathrm{P}_{\text {wind }}$ and the mechanical power $\left(\mathrm{P}_{\text {mech }}\right)$ produce by wind turbine is given in equation (6):

$$
\mathrm{P}_{\text {mech }}=\mathrm{K}_{\mathrm{p}} \mathrm{P}_{\text {wind }}
$$


where $\mathrm{Kp}$ is the power coefficient, depends on type and operating condition of wind turbine. This coefficient can be expressed as a function of tip speed ratio and pitch angle. $\mathrm{P}_{\text {mech }}$ can be expressed as in equation (7):

$$
P_{\text {mech }}=\frac{\rho \pi r^{2} v^{3} K_{p}}{2}
$$

where $r$ is the radius of the blade $(\mathrm{m})$.

\subsection{STATCOM Operational scheme in grid connected wind energy system}

The STATCOM is a three-phase voltage source inverter having a capacitor on its dc link and connected at the Point of Common Coupling (PCC). The STATCOM injects a compensating current of variable magnitude and frequency component at the PCC. STATCOM is the static counterpart of the rotating synchronous condenser. The function of STATCOM is to perform voltage regulation in a more robust manner.

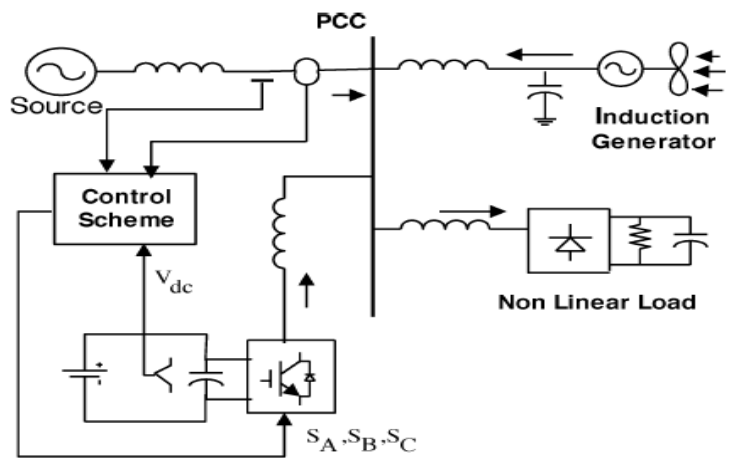

Fig.3 STATCOM control scheme

A block diagram of the proposed scheme is shown in Fig. 3. The shunt connected STATCOM using battery energy storage is interfaced with induction generator and non-linear load at PCC in the grid system. The STATCOM output is varied according to a controlled strategy, so as to maintain, power quality norms in the grid system. The current control strategy defines the functional operation of the STATCOM in the power system. A single STATCOM using IGBT is proposed to provide reactive power support, to the induction generator and nonlinear load present in the grid system.

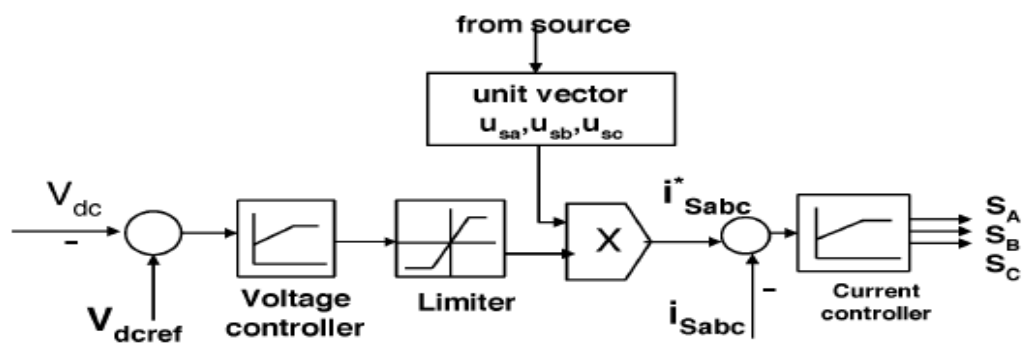

Fig.4 Control system scheme

The control system scheme, for generating the switching signals to the STATCOM is shown in Fig.4. The control scheme approach is based on injecting the currents into the grid, using current controller. The controller uses a hysteresis based current control technique. Using such technique, the controller keeps the control system variable between boundaries of hysteresis area and gives correct switching signals for STATCOM operation. The control algorithm needs the measurement of several variables such as three-phase source current $\mathrm{I}_{\mathrm{Sabc}}$, dc voltage $\mathrm{V}_{\mathrm{dc}}$, inverter current $\mathrm{I}_{\mathrm{iabc}}$ with the help of a sensor. The reference current $\mathrm{I}^{*}$ Sabc is given as input to current control block. The actual current $\mathrm{I}_{\mathrm{Sabc}}$ is subtracted from the reference current so as to activate the operation of STATCOM in current control mode. 


\section{Results And Discussion}

\subsection{Simulink Model of the proposed scheme}

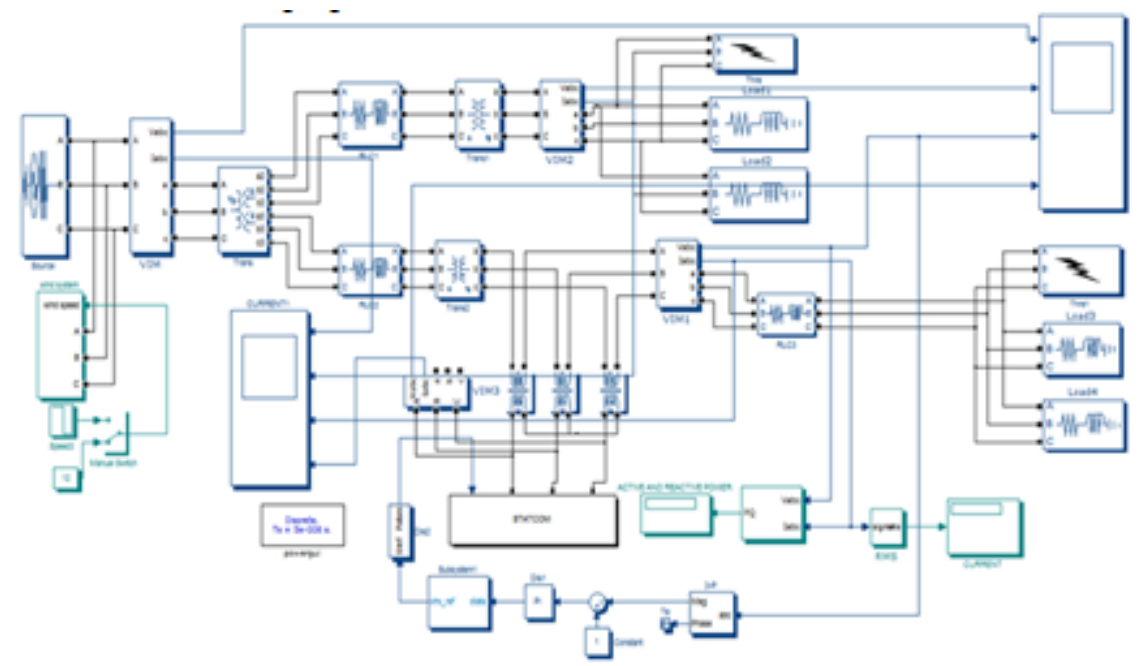

Fig.5 SIMULINK model of the grid connected wind energy system simulated for $3 \phi$ fault with STATCOM

The proposed system is modelled and simulated using in MATLAB-SIMULINK. The Fig.5 shows the Simulink model with STATCOM. In the system, three phase fault is simulated and the voltage sag is detected by using the voltage and current controllers. With the help of STATCOM voltage is injected into the bus through reactive power compensation. Base MVA of the system is chosen as 100 . The system is simulated using Intel (R) core (TM) i5-2430M processor with a speed of $2.4 \mathrm{GHz}$ and $6 \mathrm{~GB}$ RAM for a maximum fault current of $52 \mathrm{~A}$ for one second.

\subsection{Numerical Analysis}

The detailed numerical analysis of various grid and PQ parameters to validate the proposed approach is illustrated in Table 1. and Table 2.

Table 1. Grid parameters

\begin{tabular}{|c|l|l|}
\hline S.No. & Parameters & Ratings \\
\hline 1 & Grid Voltage & $25 \mathrm{KV}$ \\
\hline 2 & Induction Motor/Generator & $13 \mathrm{KV}, 50 \mathrm{~Hz}, 3 \phi, \mathrm{Yg}$ \\
\hline 3 & Line Series Inductance & $0.4806 \mathrm{mH}$ \\
\hline 4 & Inverters Parameters & $3 \phi, \mathrm{IGBT}$ based inverter, $5 \mathrm{KV}$ \\
\hline 5 & IGBT Rating & $33 \mathrm{KV}$, \\
\hline 6 & Load Parameter & $\mathrm{Vn}=1 \mathrm{KV}, 50 \mathrm{~Hz}, \mathrm{P}_{\mathrm{L}}=1 \mathrm{KW}, \mathrm{Q}_{\mathrm{L}}=500 \mathrm{VAr}$ \\
\hline
\end{tabular}

Table 1. shows that parameters and rating of the designed model which is simulated. The grid voltage under consideration is $25 \mathrm{KV}$. It is equipped with on induction machine of $13 \mathrm{KV}, 50 \mathrm{~Hz}, 3 \phi, \mathrm{Y}_{\mathrm{g}}$. The series inductance of transmission line is $0.4806 \mathrm{mH}$. The control scheme is designed using a $3 \phi$ IGBT based inverter rated at $5 \mathrm{KV}$. The load parameters are also shown in the table.

Table 2. Power quality parameters with and without STATCOM

\begin{tabular}{|c|c|c|c|}
\hline \multirow[b]{2}{*}{ Measuring parameter } & \multirow[b]{2}{*}{ Base case } & \multicolumn{2}{|c|}{ With Fault } \\
\hline & & $\begin{array}{c}\text { Without } \\
\text { STATCOM }\end{array}$ & With STATCOM \\
\hline Reactive Power (KVAr) & 40.09 & 81.48 & 103.3 \\
\hline Bus Voltage (KV) & 9 & 5 & 8 \\
\hline Bus Current (A) & 5.833 & 11.6 & 10 \\
\hline THD current (\%) & 0.93 & 1.03 & 0.33 \\
\hline THD voltage $(\%)$ & 0.17 & 0.98 & 0.19 \\
\hline
\end{tabular}

Table 2. shows the numerical analysis of the grid connected system with and without STATCOM. The base case reactive power is $40.09 \mathrm{KVAr}$. Under fault condition, the reactive power without STATCOM is 
81.48KVAr. By using STATCOM, the reactive power is increased to 103.3KVAr for better load performance. The bus voltage for the base case is $9 \mathrm{KV}$ and is reduced (voltage sag) to $5 \mathrm{KV}$ which is compensated to $8 \mathrm{KV}$ by using STATCOM. Under fault condition the bus current is $11.6 \mathrm{~A}$ which is reduced to $10 \mathrm{~A}$ with the presence of STATCOM.The THD of the base current waveform is $0.93 \%$. The THD during fault condition is increased to $1.03 \%$ which is reduced to $0.33 \%$ using STATCOM. The THD of the source voltage waveform is $0.17 \%$. The THD during voltage sag is increased to $0.98 \%$ which is reduced to $0.19 \%$ with the help of STATCOM. Reduction in THD values of voltage and current is the indication of mitigation of harmonics. Thus with the presence of STATCOM the bus voltage level is maintained within the permissible limits and helps to overcome voltage sag during three phase fault. It is inferred that the reactive power compensation achieved by means of shunt connected FACTS device namely STATCOM aids the mitigation of voltage sag and harmonics in the system during three phase fault condition.

\subsection{Graphical Analysis}

\subsubsection{Output voltage waveforms}

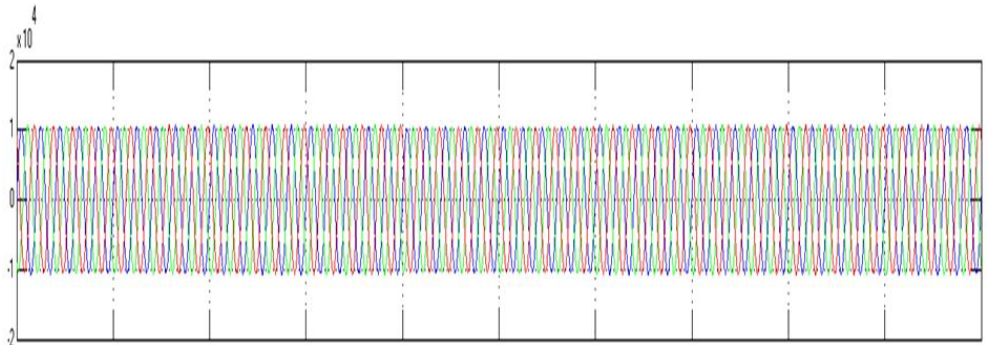

Fig.6 (a) Source Voltage waveform

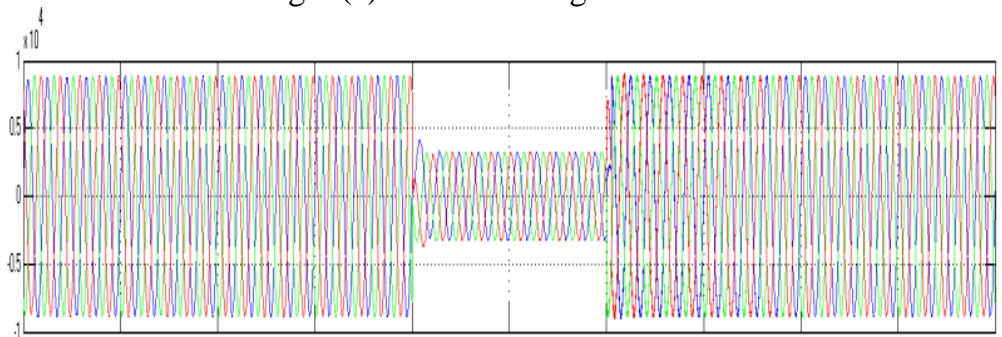

Fig.6 (b) Voltage waveform with Sag

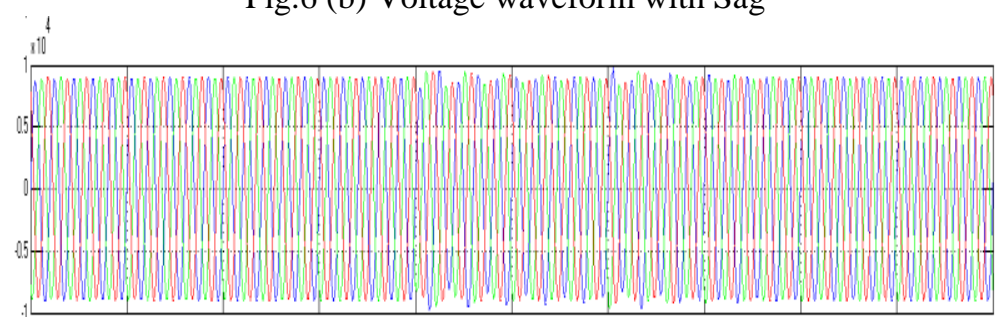

Fig.6 (c) Compensated Voltage Waveform

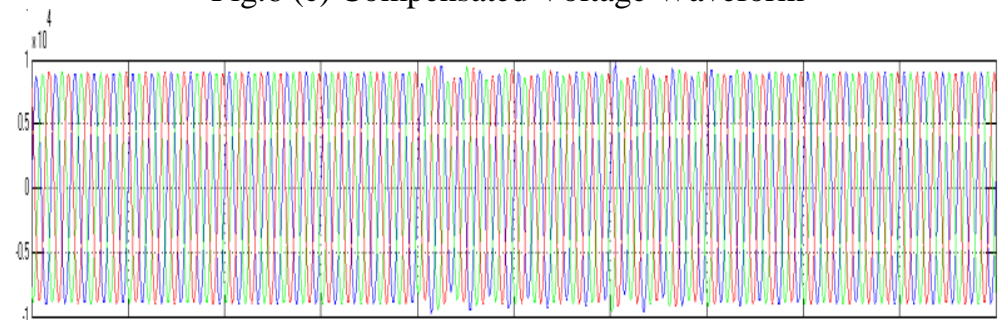

Fig.6 (d) STATCOM output Voltage

Fig.6 (a-d) shows the output voltage waveform for the base case, system with voltage sag, when the system is simulated with three phase fault, output voltage after compensation and the voltage of the compensating device STATCOM. Fig.6 (a) is the output voltage of the system during normal operation without any fault. The proposed system is then simulated for three phase fault. The output voltage waveform of the system with voltage sag during the corresponding fault condition is shown in Fig.6 (b). The control system operation begins by offering reactive power compensation in order to mitigate the voltage sag. The output voltage waveform of the system during fault with the presence of STATCOM indicates mitigation of voltage 
sag, is shown in Fig.6 (c). The output voltage waveform of the STATCOM is shown in Fig.6 (d). Thus STATCOM helps to overcome voltage sag caused in the system during the simulation of three phase fault.

\subsubsection{Output current waveforms}

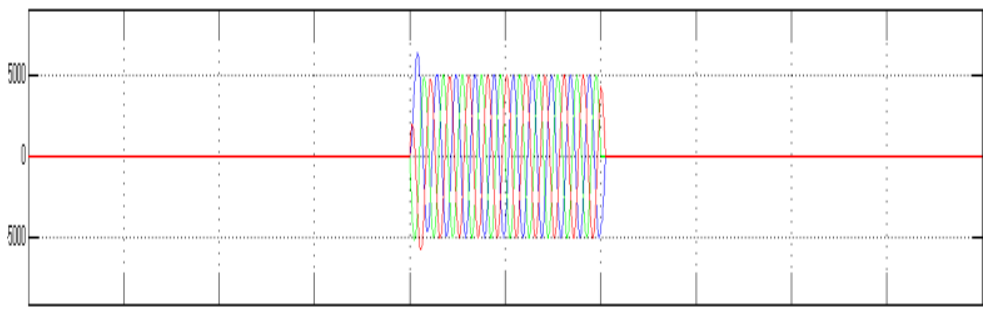

Fig.7 (a) Source Current Waveform

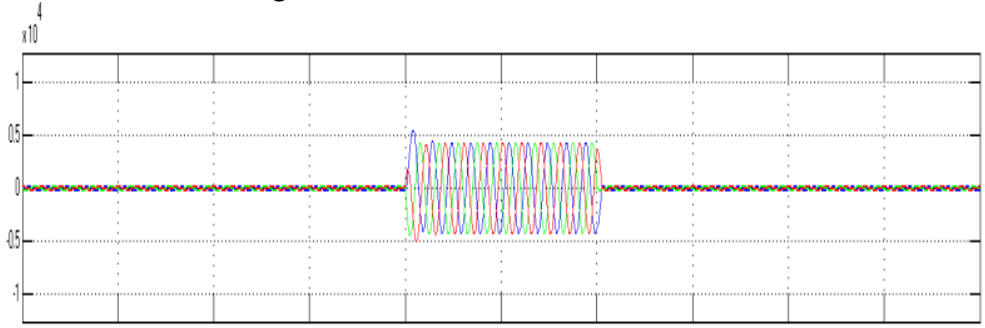

Fig.7 (b) Current Waveform during Fault

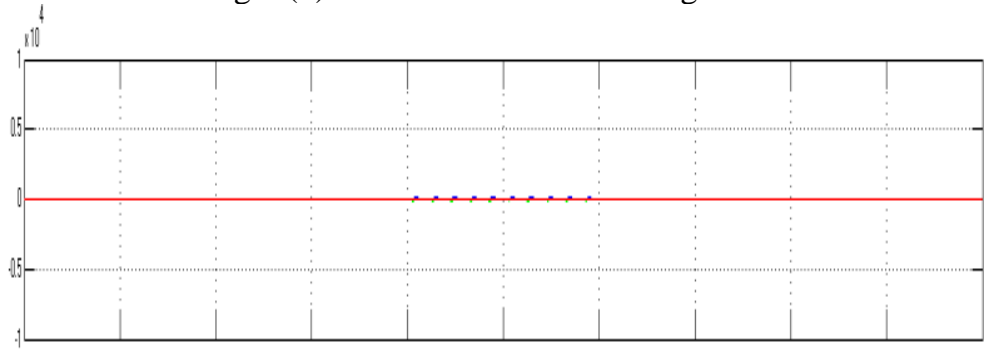

Fig.7 (c) Current Waveform with reduced Harmonics

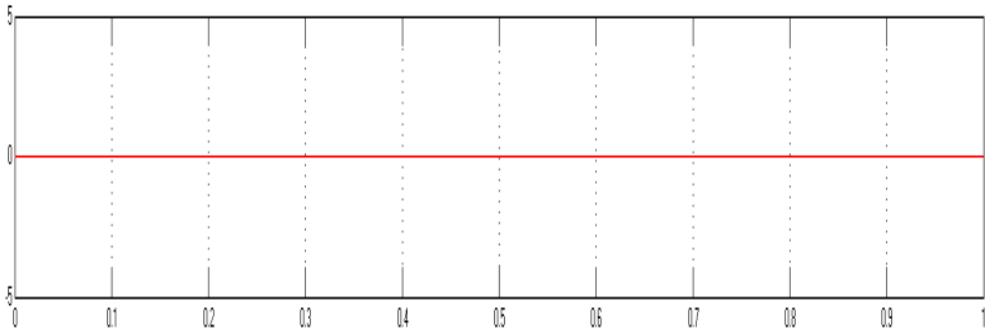

Fig.7 (d) STATCOM Output Current

Fig.7 (a-d) shows the output current waveform for the base case, harmonics during fault, final output current with reduced harmonics and the current of the compensating device STATCOM. STATCOM helps to overcome voltage sag and harmonics caused in the system during the simulation of three phase fault. The harmonic components present in the system during normal condition and during three phase fault condition is shown in Fig.7 (a-b). The control system begins its operation in order to mitigate the harmonics. The output current waveform of the system during fault with the presence of STATCOM indicates the mitigation of harmonic content is shown in Fig.7 (c). The output current waveform of the STATCOM is shown in Fig.7 (d). Thus STATCOM helps to overcome harmonics generated in the system during the simulation of three phase fault. 


\subsubsection{FFT analysis of current and voltage THD}

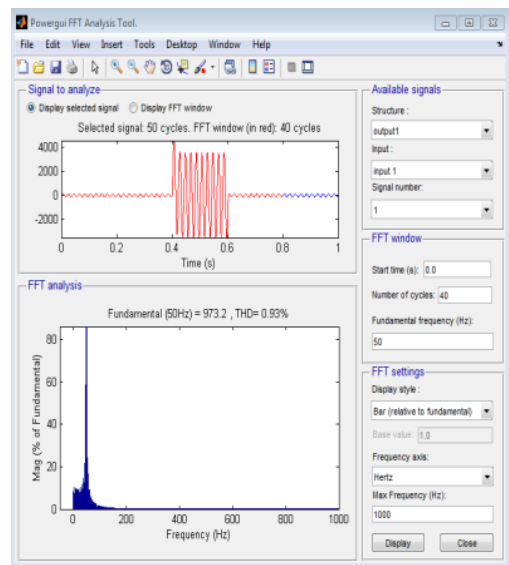

Fig.8 (a) THD spectrum for source current waveform

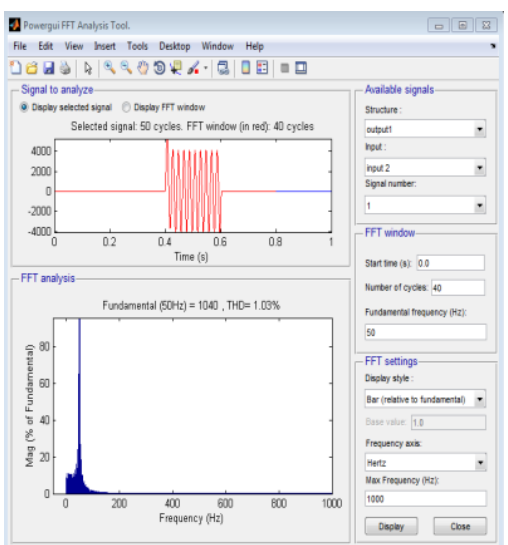

Fig.8 (b) THD spectrum for fault current waveform

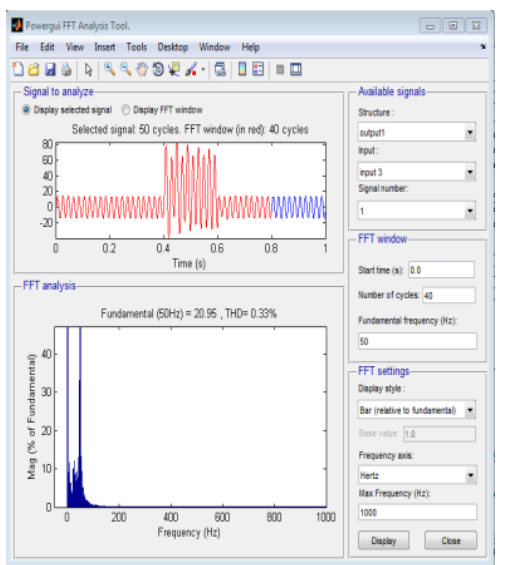

Fig. 8 (c) THD spectrum for current using STATCOM

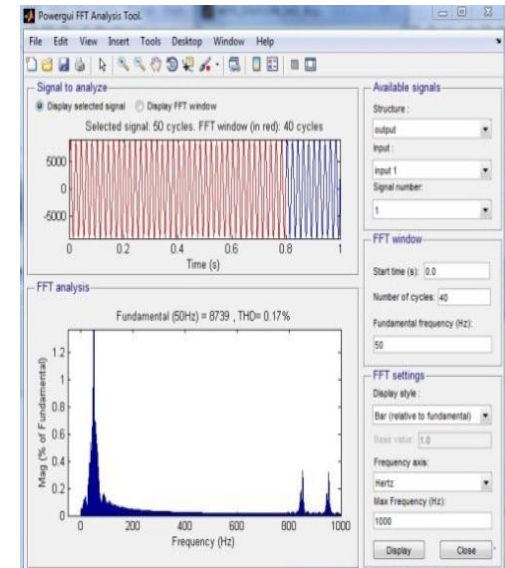

Fig.9 (a) THD spectrum for source voltage waveform

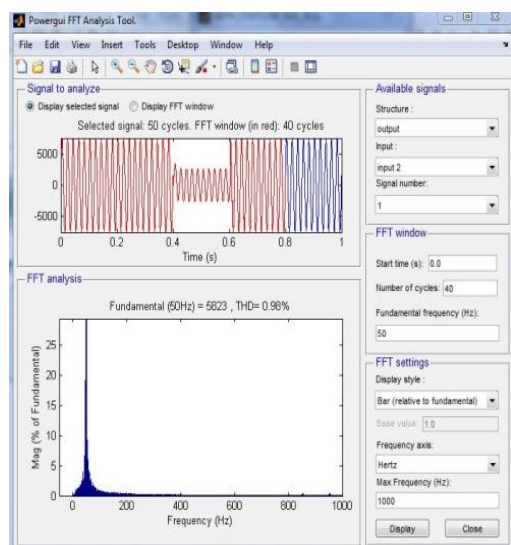

Fig.9 (b) THD spectrum for fault voltage waveform

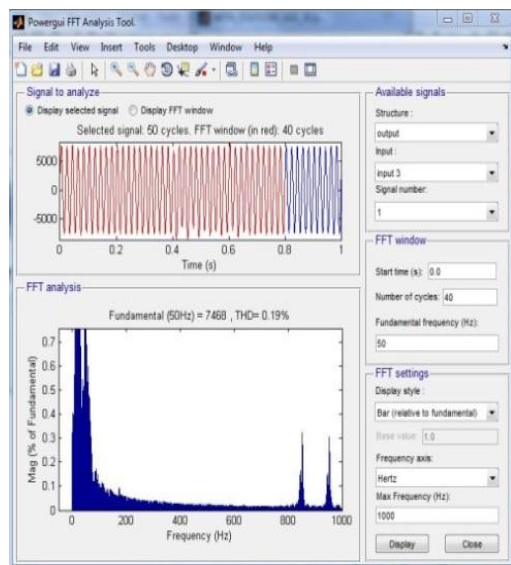

Fig.9 (c) THD spectrum for voltage using STATCOM

Fig.8 (a-c) and Fig.9 (a-c) shows the THD spectrum for output current and voltage waveforms using Fast Fourier Transformation (FFT) analysis respectively. The THD of the source current waveform is $0.93 \%$ whereas the THD during fault condition is increased to $1.03 \%$ which is reduced to 0.335 using STATCOM. The THD of the source voltage waveform is $0.17 \%$ whereas the THD during voltage sag is increased to $0.98 \%$ which is reduced to $0.19 \%$ using STATCOM. 


\section{Conclusion}

The proposed system has been modelled, simulated and analyzed using MATLAB. It is found that the bus voltage is maintained within the permissible range to ensure the quality of power using STATCOM. The bus voltage increases with the increase in the magnitude of injected voltage and at the same time the reactive power compensation has been carried out successfully. Overall power quality can be improved not only by placing STATCOM but also various FACTS devices at load buses. STATCOM is a most efficient device and it has a higher energy capacity compared to other FACTS devices. It is smaller in size and cost is less.

In future the work can be extended by connecting various FACTS devices like TCSC, SVC, UPFC etc., to the proposed system. It is also planned to solve other power quality problems. Multi-type FACTS devices can be used to deal with other power quality issues like voltage swell, transients and waveform distortion.

\section{Acknowledgements}

The authors are grateful to the management, the Principal and the Head of the Department, of PSNA College of Engineering and Technology, Dindigul, Tamil Nadu, India for providing all facilities for the research work.

\section{References}

[1]. M. Noroozian et al., "Improving power system dynamics by series connected FACTS devices," IEEE transactions Power Delivery, vol. 139, no.4, pp. 689-694, October, 1997

[2]. Z. Huang et al., "Application of UPFC in interconnected power systems- Modelling, interface, control strategy, and case study", IEEE Transactions Power System, vol. 15, no. 2, pp. 817-824, May 2000

[3]. Enrique Acha, Hugo Ambriz-perez, "FACTS -Modelling and Simulation in Power Network".

[4]. Dugan, R. C., McGranaghan, M. F., Surye Santoso., and Wayne Beaty, H, "Electrical Power System Quality". Tata McGraw-Hill Edition, 2008

[5]. Sankaran, C, "Power Quality", CRC Press LLC, 2002.

[6]. Dr. K.Ravichandrudu, P.Suman Pramod Kumar, V.E.Sowjanya, "Mitigation of harmonics and power quality improvement for grid connected wind energy system using UPFC", International Journal of Application or Innovation in Engineering \& Management (IJAIEM) Vol. 2, Issue 10, October 2013

[7]. Hingorani, N. G. "FACTS Technology - State of the Art, Current Challenges and the Future Prospects", Life Fellow, IEEE, 2007.

[8]. Milanovic, J. V, Yan Zhang, "Modelling of FACTS Devices for Voltage Sag Mitigation Studies in Large Power Systems", IEEE Transactions on Power Delivery, Vol. 25, No. 4, October, 2010

[9]. Jon Andoni Barrena, Student Member, IEEE, Luis Marroyo, Member, IEEE,Miguel Ángel Rodríguez Vidal, Member, IEEE, and José Ramón Torrealday Apraiz, "Individual Voltage Balancing Strategy for PWM Cascaded H-Bridge Converter- Based STATCOM" IEEE Transactions Industrial Electronics,vol.55, no.1, January2008.

[10]. N.G.Hingorani and L.Gyugyi "Understanding FACTS", IEEE Press, 2000, New York.

[11]. G. Sundar and S, Rama Reddy "Multilevel inverter based STATCOM for power quality enhancement in multi bus system" the Annals of "dunarea de Jos" university of Galati 2010.

[12]. Sharad W. Mohod, Member, IEEE, and Mohan V. Aware, "A STATCOM-Control Scheme for Grid Connected Wind Energy System for Power Quality Improvement”, IEEE Systems Journal, Vol. 4, No. 3, September 2010

[13]. B.T.Ramakrishnarao, B.Eswararao, L.Narendra, K.Pravallika," "A Statcom-Control Scheme for Power Quality Improvement of Grid Connected Wind Energy System", International Journal of Engineering Science and Innovative Technology (IJESIT) Volume 2, Issue 3, May 2013.

[14]. David Houcque., Introduction to Matlab for Engg. Student's. Version 1.2, August 2005. 